\title{
The effect of redundant patterns on retardate discrimination learning '
}

\author{
LESTER M. HYMAN \\ STANFORD UNIVERSITY ${ }^{2}$
}

Eight retarded children ran in a two-choice simultaneous visual discrimination task under four stimulus conditions. Condition 1 used two common objects as stimuli, Condition 2 used two pictures of common objects as stimuli, Condition 3 used two stimulus cards each containing two different pictures and Condition 4 used two stimulus cards each containing two identical pictures. Condition 4 was easiest and Condition 3 hardest for the S. Conditions 1 and 2 were intermediate and approxinately equal in difficulty.

It is generally accepted that ease of learning of visual discrimination problems is a function of the number of relevant cues or dimensions. Several studies (House \& Zeaman, 1960; Osler \& Kofsky, 1965; Restle, 1955) show a decrease in the number of errors and of the number of trials to criterion as the number of relevant redundant dimensions is increased. In the studies cited the various cues and dimensions manipulated have always been aspects of relatively unitary stimuli such as colored forms. In such cases either color or form or both are relevant. Since retarded children have difficulty solving simple two-choice simultaneous color, form, or color-form discrimination problems but have less difficulty with "junk" object problems, which are assumed to contain a larger number of redundant dimensions (House \& Zeaman, 1960), it was hypothesized that any method of increasing the amount of stimulus redundancy relevant to learning would lead to more rapid learning.

One possibility for increasing stimulus redundancy would be to increase the number of unitary stimuli that compose a single discriminandum. Simply, it was reasoned that a discriminandum containing two color patterns, where all aspects of the patterns are relevant, would contain more redundant aspects than a discriminandum consisting of a single color pattern and such problems would be easier to solve. Displays containing two patterns per stimulus have been used in similarity and oddity experiments (Scott, 1964) and have been termed "double-stimulus" displays.

\section{Method}

Twenty retarded institutionalized children with MAs ranging from 33 to 58 months and IQs ranging from 17 to 42 were selected without regard to diagnostic category or previous experience from children attending the Longley School, Mansfield State Training School.

A modified version of the WGTA was used. It consisted of a table with a sliding tray for presentation of stimuli and a one-way mirror between $\mathbf{E}$ and $\mathrm{S}$. Two 2-1/2 in. food cups were set into a $30 \mathrm{in}$. tray, centered 12 in. apart. The tray was pulled out of sight behind the one-way screen for placing of stimuli and rewards, and pushed directly in front of the Ss to begin a trial.

Stimuli. Junk objects: Sixteen pairs of junk objects that differed multidimensionally in color and shape were chosen for each $\mathrm{S}$ from the collection on hand.

Single patterns: Eighty different junk patterns (pictures cut from magazines and books, varying in color and shape) were centered on white cards ( $7 \times 3-1 / 2$ in.). The 80 stimuli were randomly paired to give 40 twochoice single pattern problems.

Double patterns: One hundred sixty different junk patterns were randomly paired and each pair mounted on a white card ( $7 \times 3-1 / 2$ in.). One pattern of a pair was centered on the left half of the card. A black line was drawn down the center of the card separating the two patterns. The 80 double-stimulus cards were randomly paired to give 40 two-choice double-stimulus problems.

Repeated patterns: Two each of 40 different junk patterns were pasted on white cards similar to the double-pattern stimuli. A black line was drawn down the center of each card separating the two identical patterns. The $\mathbf{4 0}$ repeated pattern stimulus cards were randomly paired to give 20 two-choice problems. Design and Procedure. The experiment was divided into two sections. In Section 1 the Ss were presented object, single pattern, and double pattern problems and in Section 2 the Ss were presented single pattern, double pattern, and repeated pattern problems. Half of the Ss ran first in Section 1, and then in Section 2, and the remaining half of the Ss did the reverse.

Section 1: The Ss received a total of 40 single pattern, 40 double pattern, and 16 object problems. Each problem was run for three trials. Eight different three trial position sequences were used for each Seach day, with four of the sequences being used twice. Each $S$ received five single pattern, five double pattern, and two object problems each day for eight days. The single and double pattern problems were presented in a different mixed order each day and the two object problems were presented as the first and last problems each day.

Section 2: The Ss received a total of 20 single pattern, 20 double pattern, and 20 repeated pattern problems. Four problems of each type were presented to each $S$ each day. The remainder of the procedure was identical to Section 1.

Pretraining. The Ss received four pretraining problems, each run to a criterion of $20 / 25$ correct in one day within five days. Problem 1 was a junk object discrimination and the remaining three problems were 
one each of the single, double, and repeated pattern problems. The order of the last three problems varied for Ss. If an $\mathrm{S}$ met criterion on all four problems, he was admitted to the experimental procedure.

General Procedure. The E led the Sto an experimental cubicle and seated him on one side of the apparatus. To begin a trial, E pushed the baited tray in front of $\mathrm{S}$. Two stimuli were displayed covering the food cups. An M\&M candy was placed under the correct stimulus. In addition, E said "good," if the first choice was correct, and "no," if it was not. Immediate correction was allowed. Since all Ss had previously served in experiments using a similar procedure, no other instructions were given.

\section{Results}

Eight Ss failed in pretraining and were dropped from the experiment. An additional four Ss were dropped from the experiment because of a ceiling effect on learning. A criterion of five errors or less on Trials 2 and 3 of the first 48 problems was adopted to eliminate $S s$ whose performance was near perfect.

In Section 1, the mean percentage of correct responses averaged over Trials 2 and 3 and Ss was $71.9 \%$ for objects, $72.2 \%$ for single patterns, and $65.9 \%$ for double patterns. A four-way analysis of variance on trials, days, Ss, and the single and double pattern conditions showed all four variables to be significant $(p<.05)$. None of the possible interactions was significant.

In Section 2, the mean percentage of correct responses averaged over Trials 2 and 3 and Ss was $77.2 \%$ for repeated patterns, $70.0 \%$ for single patterns, and $66.1 \%$ for double patterns. The results for single patterns and double patterns did not differ significantly from those found in Section 1. A four-way analysis of variance on trials, days, Ss, and the three conditions showed significant effects of trials, Ss, and conditions $(p<.05)$, and days and all interactions proved nonsignificant. $T$ tests among the three conditions showed repeated patterns to be significantly more discriminable than single patterns $(t=2.60, d f=159, p<.01)$ and averaged repeated and single patterns to be more discriminable than double patterns $(t=2.59, d f=159, p<.01)$.

\section{Discussion}

Comparison among the three experimental conditions, single, double, and repeated patterns, indicates that type of redundancy as well as amount of redundancy affects visual discrimination learning by retardates. It appears that increasing the number of different redundant cues in a double-stimulus display as in the double pattern condition retards rather than facilitates learning. At least two other studies (House, 1966; Hyman, 1964) show that type of redundancy as well as amount of re- dundancy in single pattern displays affects discrimination learning. A possible explanation of the effects of various types of redundancy of double-stimulus displays on learning is suggested by Cahn (1966). Cahn's work shows that increasing the number of differences between the two color patterns of a double-stimulus discriminandum retards learning. Cahn suggests that a distinction be made between "within" redundancy (redundancy of different parts of a stimulus) and 'between" redundundancy (redundancy in cues distinguishing two stimuli). Zeaman \& House's (1963) attention theory suggests a mechanism which might predict the results of this experiment. If retarded children have limited "attention" then in the double pattern condition they may attend to only one of the two patterns of a stimulus on a given trial. On a subsequent trial they may attend to the previously unnoticed pattern and be forced to guess at a solution. This would make double patterns more difficult to learn than single patterns. In the case of repeated patterns it would not matter which of the two patterns of a stimulus the $S$ attended to as they are identical, but the repetition would make a repeated pattern "larger" in some manner (in this experiment more of the area of the stimulus card was covered by the patterns in the repeated pattern problems than in the single pattern problems), and thus repeated patterns would be easier to learn than single patterns.

\section{References}

CAHN, T. I. The role of redundancy in discrimination learning by normal and mentally retarded children. Unpublished doctoral dissertation, University of Connecticut, 1966.

HOUSE, B. J. Discrimination of symmetrical and asymmetrical dot patterns by retardates. J. exp. child Psychol, 1966, 3, 377-389.

HOUSE, B. J., \& ZEAMAN, D. Transfer of a discrimination from objects to patterns. J. exp. Psychol, 1960, 59, 298-302.

HYMAN, L. M. Symmetry, numerosity and partial identity as stimulus factors in retardate discrimination learning. Unpublished doctoral dissertation, University of Connecticut, 1964.

OSLER, S. F., \& KOFSKY, E. Stimulus uncertainty as a variable in the development of conceptual ability. J. exp. child Psychol., 1965, 2, 264279.

RESTLE, F. A theory of discrimination learning. Psychol Rev., 1955, $62,11-19$.

SCOTT, K. G. A comparison of similarity and oddity, J. exp. child Psychol., 1964, 1, 123-133.

ZEAMAN, D., \& HOUSE, B. J. The role of attention in retardate discrimination learning. In N. R. Ellis (Ed.), Handbook of mental deficiency. New York: McGraw-Hill, 1963. Pp. 159-223.

\section{Notes}

1. This research was supported by Research Grant M-1099 from the National Institute of Mental Health, Public Health Service, and was conducted at the Psychological Laboratories of the Mansfield State Training School, Mansfield, Connecticut, with the aid of Dr. David Zeaman and Dr. Betty House.

2. Presently at Michigan State University. 